\title{
Metal organic vapor-phase epitaxy of InAs/InGaAsP quantum dots for laser applications at $1.5 \mathrm{~m}$
}

Semenova, Elizaveta; Kulkova, Irina; Kadkhodazadeh, Shima; Schubert, Martin; Yvind, Kresten

Published in:

Applied Physics Letters

Link to article, DOI:

$10.1063 / 1.3634029$

Publication date:

2011

Document Version

Publisher's PDF, also known as Version of record

Link back to DTU Orbit

Citation (APA):

Semenova, E., Kulkova, I., Kadkhodazadeh, S., Schubert, M., \& Yvind, K. (2011). Metal organic vapor-phase epitaxy of InAs/InGaAsP quantum dots for laser applications at $1.5 \mathrm{~m}$. Applied Physics Letters, 99(10), 101106. https://doi.org/10.1063/1.3634029

\section{General rights}

Copyright and moral rights for the publications made accessible in the public portal are retained by the authors and/or other copyright owners and it is a condition of accessing publications that users recognise and abide by the legal requirements associated with these rights.

- Users may download and print one copy of any publication from the public portal for the purpose of private study or research.

- You may not further distribute the material or use it for any profit-making activity or commercial gain

- You may freely distribute the URL identifying the publication in the public portal 


\title{
Metal organic vapor-phase epitaxy of InAs/InGaAsP quantum dots for laser applications at $1.5 \mu \mathrm{m}$
}

\author{
E. S. Semenova, ${ }^{1, a)}$ I. V. Kulkova, ${ }^{1}$ S. Kadkhodazadeh, ${ }^{1,2}$ M. Schubert, ${ }^{1, b)}$ and K. Yvind ${ }^{1}$ \\ ${ }^{1}$ DTU Fotonik, Department of Photonics Engineering, Technical University of Denmark, \\ Ørsteds Plads Bldg. 343, 2800 Kongens Lyngby, Denmark \\ ${ }^{2}$ DTU Cen, Center for Electron Nanoscopy, Technical University of Denmark, \\ Building 307, 2800 Kongens Lyngby, Denmark
}

(Received 1 June 2011; accepted 13 August 2011; published online 8 September 2011)

\begin{abstract}
The epitaxial growth of InAs/InGaAsP/InP quantum dots (QDs) for emission around $1.5 \mu \mathrm{m}$ by depositing a thin layer of GaAs on top of the QDs is presented in this letter. The infuence of various growth parameters on the properties of the QDs, in particular, size, shape, chemical composition, and emission wavelength are investigated. Continuous wave lasing in ridge waveguide QD laser structures in the $1.5 \mu \mathrm{m}$ wavelength range is demonstrated. (C) 2011 American Institute of Physics. [doi:10.1063/1.3634029]
\end{abstract}

Quantum dots (QDs) are of great interest for ultrafast optical devices, in particular, as a gain medium for modelocked lasers, ${ }^{1}$ due to their unique carrier dynamics. ${ }^{2,3}$ Considerable work has been carried out in the fabrication of InAs/GaAs QDs, and impressive results have been reported on mode-locked QD lasers in the $1.3 \mu \mathrm{m}$ wavelength region. $^{4,5}$ The way to extend the emission wavelength of QDs to the $1.5 \mu \mathrm{m}$ range is the development of QD growth in the InP material system, which is also compatible with photonic integration.

Promising results were demonstrated in the InAs/InP systems, such as QD-laser structures emitting at $1.59 \mu \mathrm{m}$ with a rather low threshold current density of $190 \mathrm{~A} / \mathrm{cm}^{2}$ from a broad area device. ${ }^{6}$ This structure was grown by gassource molecular beam epitaxy on a (113)B wafer. However, growth on exact (001) wafers with this epitaxial technique likely leads to formation of quantum dashes. ${ }^{7}$ To grow Stranski-Krastanow (SK) QDs on exact (001) InP wafers metal organic vapor-phase epitaxy (MOVPE) as epitaxial technique can be used. ${ }^{8}$

Due to a lower lattice mismatch in the InAs/InP (3\%) system in comparison to InAs/GaAs (7\%), the size of selfassembled InAs QDs grown on InP is larger, and thus, their corresponding emission wavelength exceeds $1.65 \mu \mathrm{m}$. Recently, it has been demonstrated that the emission wavelength of these QDs can be tuned to the desired $1.5 \mu \mathrm{m}$ wavelength region by using the double capping technique, ${ }^{6,9}$ by growing a thin GaAs underlayer, ${ }^{8}$ or very low V/III ratio and low growth temperature. ${ }^{10,11}$

In this article, a different method to achieve $1.5 \mu \mathrm{m}$ emission from InAs/InGaAsP/InP QDs by depositing a thin GaAs capping layer on top of the InAs QDs is presented and discussed. The influence of the growth conditions on the QD characteristics is studied, and finally, continuous wave (CW) laser operation of structures based on these QDs is demonstrated.

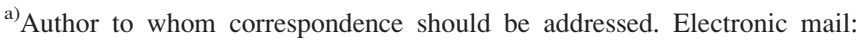
esem@fotonik.dtu.dk.

b) Now at University of Constance, Department of Physics, 78464 Konstanz, Germany.
}

All samples were grown in a low-pressure MOVPE reactor (Discovery 125) on an $\mathrm{InP}(001)$ substrate using $\mathrm{H}_{2}$ as the carrier gas, trimethylindium and trimethylgallium as group III precursors, and arsine, phosphine, and tertiarybutylphosphine as group $\mathrm{V}$ sources. The wafer temperature was regulated using an emissivity corrected pyrometer (RealTemp ${ }^{\circledR}$ ) system. A QD array was formed by depositing 1.5-2.5 ML of InAs at $516-525^{\circ} \mathrm{C}$ on top of an $\operatorname{In}_{0.83} \mathrm{Ga}_{0.17} \mathrm{As}_{0.38} \mathrm{P}_{0.62}$ (Q1.08) matrix layer grown at $610^{\circ} \mathrm{C}$. In one set of samples, the deposition of the QD array was followed by a $10 \mathrm{~nm}$ thick overgrowth of InGaAsP (Q1.08) at low temperature. Afterwards the temperature was ramped back up to $610^{\circ} \mathrm{C}$ to continue the growth. In the second set of samples, the InAs QDs were covered with 1.5-1.7 ML of GaAs prior to overgrowth with the InGaAsP capping layer. In both sets of samples, a second QD array was grown on top of the InGaAsP capping layer under the same conditions as the first array of QDs. The second arrays of QDs were left without further overgrowth in order to be studied by atomic force microscopy (AFM) and scanning transmission electron microscopy (STEM).

The optical properties of the QDs were evaluated by photoluminescence (PL) measurements in the temperature range 64-300 K. Morphology, size, and chemical composition of the buried dots were examined using high-angle annular dark-field (HAADF) STEM in plan-view and crosssectional geometries.

The surface QDs appeared to have hexagonal bases, elongated along the [1ํㅣㄹ direction and be multi-faceted. The AFM study also revealed that decreasing the V/III ratio from 40 to 5 during the QD formation leads to an increase in the number density of the QDs (increasing from $1.6 \times 10^{10} \mathrm{~cm}^{-2}$ to $1.9 \times 10^{10} \mathrm{~cm}^{-2}$ ) and slight decrease in the heights of the QDs (approximately 20\%). The growth temperature had a stronger influence on the QD number density, as decreasing the substrate temperature from 525 to $516^{\circ} \mathrm{C}$ increased the QD density from $1.9 \times 10^{10} \mathrm{~cm}$ to $4.2 \times 10^{10} \mathrm{~cm}^{-2}$. This can be due to reduction in the mobility of the adatoms during QD formation. The volume of the QDs was also reduced by decreasing the temperature, as the heights and base lengths of the QDs were found to decrease from approximately 8.4 to $5.5 \mathrm{~nm}$ and from 75 to $61 \mathrm{~nm}$, respectively. 
The optimal effective thickness of InAs was found to be about 1.65 ML. Increasing the effective thickness of InAs leads to increase in the sizes of the QDs, while their number density remains unchanged. A lower effective thickness of InAs leads to a lower number density while keeping the sizes of the QDs constant. Thus, the optimal QD growth conditions were found to be V/III ratio of 5, growth temperature of $516^{\circ} \mathrm{C}$, and InAs effective thickness of $1.65 \mathrm{ML}$. QDs with smallest dimensions and relatively high number density (around $4.2 \times 10^{10} \mathrm{~cm}^{-2}$ ) were achieved under these conditions.

The capping process is known to have a considerable effect on the buried dots structural properties. Crosssectional and plan-view HAADF STEM images of typical QDs in the sample without a GaAs capping layer grown under our optimal conditions are shown in Figs. 1(a) and 1(c), respectively. The InAs-rich QD appears bright in the images, as image intensity in HAADF STEM is strongly dependent on the atomic number. The QDs were on average $25.3 \pm 3 \mathrm{~nm}$ in diameter and $5.3 \pm 0.9 \mathrm{~nm}$ in height. QDs have symmetric bases without any significant elongation. A wetting layer of $\sim 2$ ML thickness was determined from the cross-sectional images. The QDs in this sample emit at a wavelength larger than $1.65 \mu \mathrm{m}$. In order to shift the emission to the desired wavelength range, we capped the QD array with a thin GaAs layer (1.7 ML), before overgrowing them fully with InGaAsP. Cross-sectional and plan-view HAADF STEM images of typical QDs in this sample are shown in Figs. 1(b) and 1(d). A significant reduction in the average heights of the QDs in this sample, compared to the QDs in Figs. 1(a) and 1(c), is clearly visible in the images. The average measured height and diameter of the QDs in this sample were $2.6 \mathrm{~nm}$ and $31.9 \pm 2 \mathrm{~nm}$, respectively. Therefore, the deposited 1.7 ML of GaAs has led to a redistribution of the QD material, by modifying the strain distribution in the system. Our detailed STEM study of this mechanism described in Ref. 12 suggested the segregation of
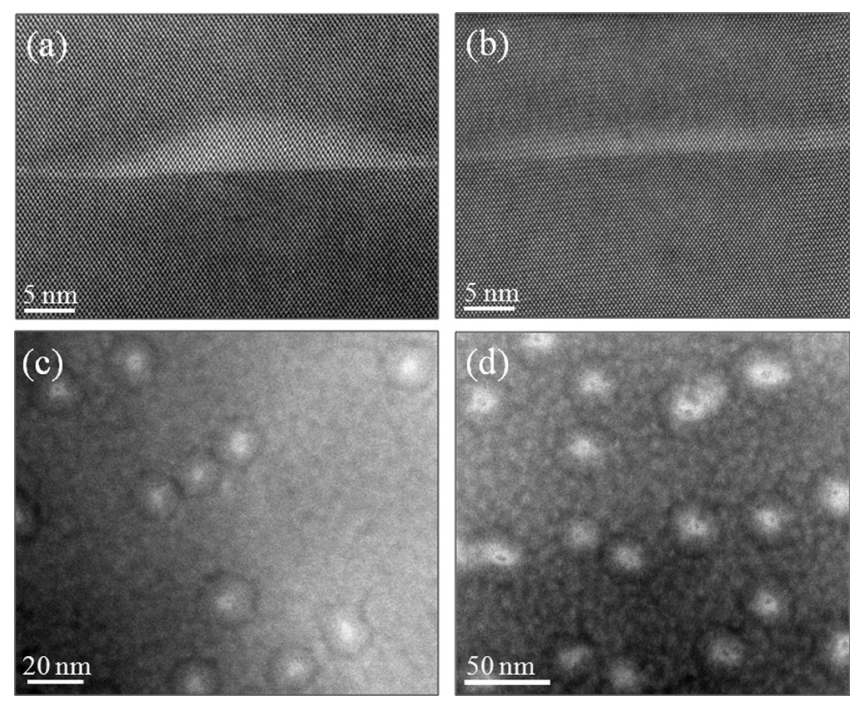

FIG. 1. Cross-sectional HAADF STEM images of QDs formed from depositing 1.65 ML of InAs in a InGaAsP matrix and capped with: (a) InGaAsP and (b) $1.7 \mathrm{ML}$ of GaAs followed by InGaAsP. (c) and (d) Plan-view HAADF STEM images of the QDs in samples (a) and (b), respectively. the deposited GaAs around the bases of the QDs. It was concluded that the deposited GaAs causes the migration of InAs away from the tops of the QDs, resulting in the observed height reduction of the QDs, and together with the removed InAs segregates around the bases of the QDs.

The dependence of the QD PL peak position at room temperature (RT) as a function of the GaAs thickness is shown in the inset in Fig. 2. By increasing the GaAs thickness, a strong blue shift occurs. In Fig. 2, the RT PL spectrum of the QDs overgrown with 1.7 ML GaAs is shown. The QD PL peak position is about $1.5 \mu \mathrm{m}$ at $300 \mathrm{~K}$ with a full width at half maximum (FWHM) of the emission of $170 \mathrm{~nm}$. Such a FWHM is a result of the QDs size distribution. PL excitation spectroscopy at $7 \mathrm{~K}$ (not shown) proves multimodal size distribution of QDs, in which the QDs height difference is an integer $1 \mathrm{ML}$ similar to the process described in Ref. 13. The temperature dependence of the PL (not shown) showed a spectrum integrated intensity ratio of around 3 between $77 \mathrm{~K}$ to RT. This indicates a high optical quality of the material.

Laser performance: In order to test the QDs as gain material, laser structures were fabricated with an active region consisting of five layers, separated by $60 \mathrm{~nm}$, of 1.65 ML InAs QDs covered with 1.7 ML of GaAs. The barriers and separate confinement region was composed of InGaAsP (Q1.08) with a total waveguide thickness of $450 \mathrm{~nm}$ sandwiched between $\mathrm{n}$-and $\mathrm{p}$-doped InP cladding layers. This structure was processed into $2 \mu \mathrm{m}$ wide ridge waveguide lasers with different cavity lengths and the devices were soldered epi-side up to AlN heatsinks. ${ }^{14}$ No facet coatings were deposited. The lasers were tested in the CW regime at RT. In Fig. 3, the light current characteristic and the voltage-current characteristic for a $4 \mathrm{~mm}$ cavity length laser are shown. Threshold currents are $275 \mathrm{~mA}$ and $400 \mathrm{~mA}$ for the 2 and 4 $\mathrm{mm}$ long devices, respectively. A thermal roll-over results in a maximum optical output of $7.3 \mathrm{~mW}$ for the $4 \mathrm{~mm}$ long device. The inset in Fig. 3 shows the electroluminescence and $\mathrm{CW}$ lasing spectra for the $4 \mathrm{~mm}$ long cavity as a function of the excitation current. The wide spectral bandwidth is a result of the QD size distribution. It lowers the efficiency of these devices since only QDs with a certain size participate on the lasing process. QDs with other sizes contribute to losses. However, a broad spectrum is a key-requirement for achieving short mode-locked laser pulse.

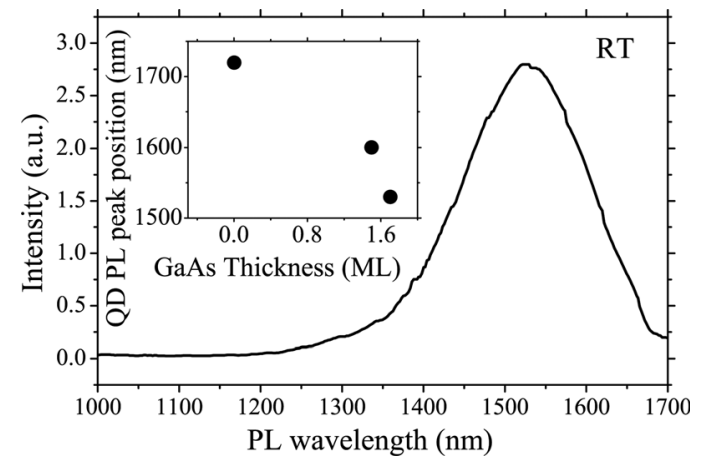

FIG. 2. The RT spectra of QDs capped with 1.7 ML of GaAs. Inset shows dependence of the QD PL peak position at RT on the thickness of the overgrown GaAs layer. 


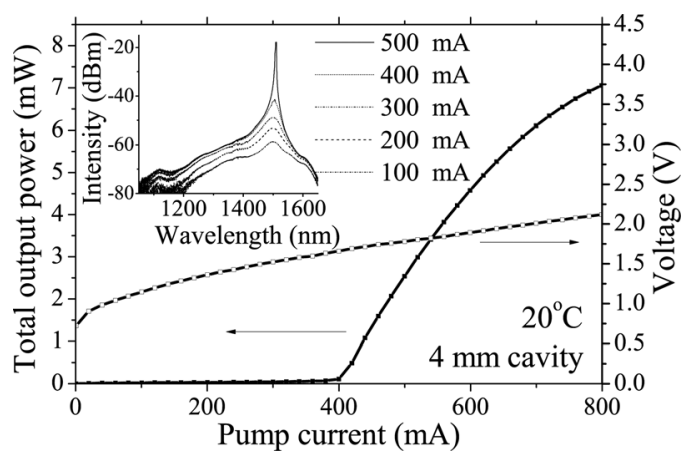

FIG. 3. CW light-current (solid squares) and voltage-current (open squares) characteristic of a $2 \mu \mathrm{m}$ wide ridge QD laser $(\mathrm{L}=4 \mathrm{~mm})$ at $20^{\circ} \mathrm{C}$ heat sink temperature. Inset shows corresponding EL and $\mathrm{CW}$ lasing spectra.

In summary, the MOVPE growth of self-assembled InAs/InGaAsP/InP QDs and the influence of growth parameters on the properties of these QDs were discussed and the optimal growth conditions of the QDs were presented. Capping the QDs with a thin GaAs layer (1.5-1.7 ML) was found to shift the emission wavelength of the QDs to the desired $1.5 \mu \mathrm{m}$ region, while retaining a high optical quality of the material. Narrow ridge lasers based on such QDs demonstrate $\mathrm{CW}$ lasing generation at RT at a wavelength of $1.5 \mu \mathrm{m}$.

This work was financially supported in part by the Danish Research Council through the research programs OPSCODER, QUEST, and through the Villum Kann Rasmussen center of excellence NATEC. ESS thanks the European
Commission for funding through the Marie Curie Incoming International Fellowship (project number 252890).

${ }^{1}$ K. Yvind, D. Larsson, J. Mørk, J. M. Hvam, M. Thomson, R. Penty, and I. White, Photonics West 2008, Paper 6909, 69090A1-9 (2008).

${ }^{2}$ T. Akiyama, M. Sugawara, and Y. Arakawa, Proc. IEEE. 95(9), 1757 (2007).

${ }^{3}$ A. Markus, J. X. Chen, C. Paranthoën, A. Fiore, C. Platz, and O. GauthierLafaye, Appl. Phys. Lett. 82(12), 1818 (2003).

${ }^{4}$ M. G. Thompson, A. Rae, R. L. Sellin, C. Marinelli, R. V. Penty, I. H. White, A. R. Kovsh, S. S. Mikhrin, D. A. Livshits, and I. L. Krestnikov, Appl. Phys. Lett. 88, 133119 (2006).

${ }^{5}$ E. U. Rafailov, M. A. Cataluna, and W. Sibbett, Nature Photon. 1, 395 (2007).

${ }^{6}$ P. Caroff, C. Paranthoen, a_ C. Platz, O. Dehaese, H. Folliot, N. Bertru, C. Labbé, R. Piron, E. Homeyer, A. Le Corre, and S. Loualiche, Appl. Phys. Lett. 87, 243107 (2005).

${ }^{7}$ G. Moreau, S. Azouigui, D.-Y. Cong, K. Merghem, A. Martinez, G. Patriarche, and A. Ramdane, Appl. Phys. Lett. 89, 241123 (2006).

${ }^{8}$ S. Anantathanasarn, R. Nötzel, P. J. van Veldhoven, F. W. M. van Otten, T. J. Eijkemans, Y. Barbarin, T. de Vries, E. Smalbrugge, E. J. Geluk, E. A. J. M. Bente, Y. S. Oei, M. K. Smit, and J. H. Wolter, J. Crystal Growth 298, 553 (2007)

${ }^{9}$ Z.G. Lu, J.R. Liu, P.J. Poole, S. Raymond, P.J. Barrios, D. Poitras, G. Pakulski, P. Grant, and D. Roy-Guay, Opt. Express 17, 13609 (2009).

${ }^{10}$ K. Kawaguchi, M. Ekawa, A. Kuramata, T. Akiyama, H. Ebe, M. Sugawara, and Y. Arakawa, Appl. Phys. Lett. 854331 (2004).

${ }^{11}$ D. Franke, M. Moehrle, J. Boettcher, P. Harde, A. Sigmund, and H. Kuenzel Appl. Phys. Lett. 91, 081117 (2007).

${ }^{12}$ S. Kadkhodazadeh, E. S. Semenova, K. Yvind, and R. E. Dunin-Borkowski, J. Cryst. Growth 329, 57 (2011).

${ }^{13}$ J. F. Carlin, R. Houdré, A. Rudra, and M. Ilegems, Appl. Phys. Lett. 59, 3018 (1991).

${ }^{14}$ K. Yvind, D. Larsson, L. J. Christiansen, C. Angelo, L. K. Oxenløwe, J. Mørk, D. Birkedal, J. M. Hvam, and J. Hanberg, Photon. Technol. Lett., 16(4), 975 (2004). 